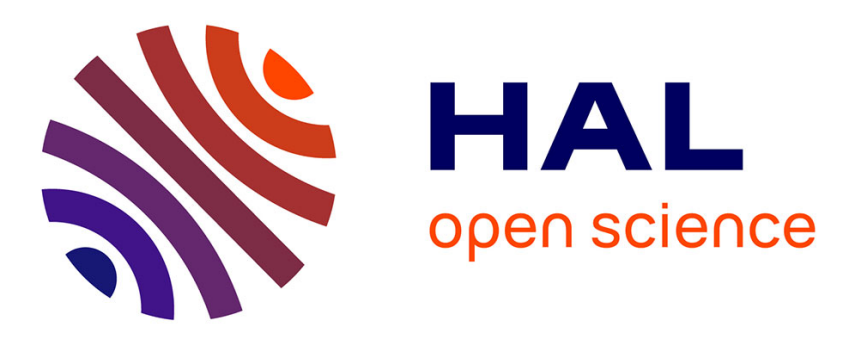

\title{
Mutual influence of cross hatch angle and superficial roughness of honed surfaces on friction in ring-pack tribo-system
}

Sabeur Mezghani, Ibrahim Demirci, Mohamed El Mansori, Mohammed Yousfi

\section{- To cite this version:}

Sabeur Mezghani, Ibrahim Demirci, Mohamed El Mansori, Mohammed Yousfi. Mutual influence of cross hatch angle and superficial roughness of honed surfaces on friction in ring-pack tribo-system. Tribology International, 2013, 66, pp.54-59. 10.1016/j.triboint.2013.04.014 hal-00914071

\author{
HAL Id: hal-00914071 \\ https://hal.science/hal-00914071
}

Submitted on 28 Jan 2014

HAL is a multi-disciplinary open access archive for the deposit and dissemination of scientific research documents, whether they are published or not. The documents may come from teaching and research institutions in France or abroad, or from public or private research centers.
L'archive ouverte pluridisciplinaire HAL, est destinée au dépôt et à la diffusion de documents scientifiques de niveau recherche, publiés ou non, émanant des établissements d'enseignement et de recherche français ou étrangers, des laboratoires publics ou privés. 


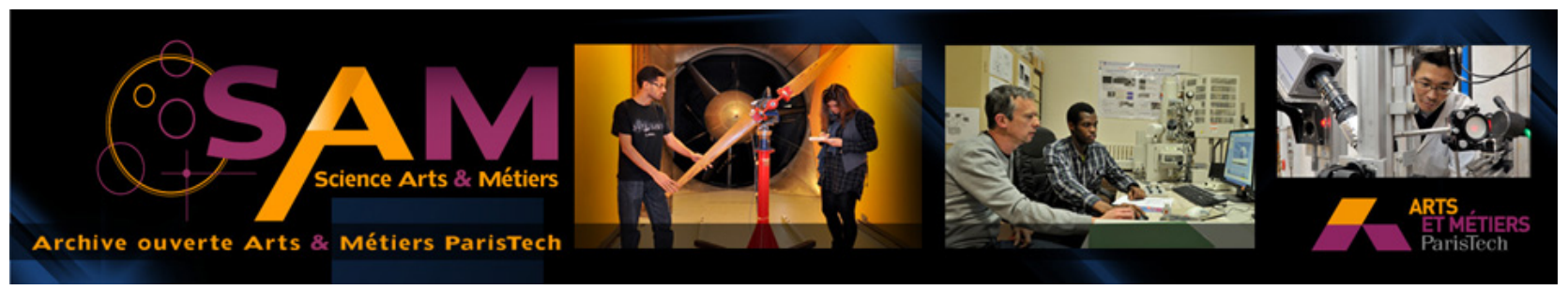

Science Arts \& Métiers (SAM)

is an open access repository that collects the work of Arts et Métiers ParisTech researchers and makes it freely available over the web where possible.

This is an author-deposited version published in: http://sam.ensam.eu

Handle ID: .http://hdl.handle.net/10985/7575

\section{To cite this version :}

Sabeur MEZGHANI, Ibrahim DEMIRCI, Mohamed EL MANSORI, Mohammed YOUSFI - Mutual influence of cross hatch angle and superficial roughness of honed surfaces on friction in ring-pack tribo-system - Tribology international - Vol. 66, p.54-59 - 2013 


\title{
Mutual influence of crosshatch angle and superficial roughness of honed surfaces on friction in ring-pack tribo-system
}

\author{
S. Mezghani, ${ }^{*}, 1$ I. Demirci ${ }^{1}$, M. El Mansori ${ }^{1}$, M. Yousfi ${ }^{1,2}$ \\ ${ }^{I}$ Arts et Métiers ParisTech, MSMP, Rue Saint Dominique, 51006 Châlons en Champagne, Cedex, France \\ ${ }^{2}$ Renault s.a.s, Direction de l'Ingénierie Mécanique, 67 rue des bons raisins, 92500 Rueil Malmaison, France \\ *Corresponding author: Tel: +33 (0)3266991 92; Fax: +33 (0)32669 91 97;
}

Email: sabeur.mezghani@ensam.eu

\begin{abstract}
The cylinder bore surface texture widely produced by honing technique, is an essential factor for a good engine performance (friction, oil consumption, running-in, wear...). This explains the improvement and development of various new honing techniques. These different honing processes generate surfaces with various texture features characteristics (roughness, valleys depth, crosshatch angle...).

This paper addresses a comparison of ring-pack friction for cylinder surfaces produced respectively by plateau honing and helical slide honing. It takes in consideration the mutual effect of superficial plateau roughness amplitude and honing angle. A numerical model is developed to predict friction within the cylinder ring-pack system in mixed lubrication regime. The results show the effectiveness of helical slide honed surface texture in comparison to plateau honed bore surfaces.
\end{abstract}

Keywords: Honing; Plateau roughness; Friction; Cylinder engine. 


\section{Nomenclature}

$\mathrm{a}_{\mathrm{h}} \quad$ Hertzian contact radius, $\mathrm{m}$

b Translation coefficient, $m$

$\mathrm{F}_{\mathrm{N}} \quad$ External applied load, $\mathrm{N}$

$\mathrm{H} \quad$ Dimensionless film thickness

$\mathrm{H}_{0} \quad$ Dimensionless rigid body displacement

M, L Moes simensionless parameters

$\mathrm{p}_{\mathrm{h}} \quad$ Hertzian pressure, $\mathrm{Pa}$

$\mathrm{p}_{\mathrm{r}} \quad$ constant, $\mathrm{p}_{\mathrm{r}}=1.96 .10^{8}$

$\mathrm{P} \quad$ Dimensionless pressure

$R_{x} R_{y}$ Radius of curvature in $x$ and y direction respectively, $m$

$\mathrm{R}$ Equivalent radius of curvature, $\mathrm{m}$

Srr Slide to roll ratio: $\mathrm{Srr}=2(\mathrm{u} 1-\mathrm{u} 2) /\left(\mathrm{u} 1+\mathrm{u}_{2}\right)$

$\mathrm{T}$ Time, $\mathrm{s}$

$\mathrm{T} \quad$ Dimensionless time: $\mathrm{T}=\mathrm{tu}_{\mathrm{m}} / \mathrm{a}_{\mathrm{h}}$

$u_{i} \quad$ Velocity of surface $i$

$\mathrm{u}_{\mathrm{m}} \quad$ mean velocity, $\left(\mathrm{u}_{1}+\mathrm{u}_{2}\right) / 2$

$\mathrm{x}, \mathrm{y}, \mathrm{z} \quad$ Space coordonates

$\mathrm{X}, \mathrm{Y}, \mathrm{Z}$ Dimensionless space coordonates

$\mathrm{z}_{\mathrm{r}} \quad$ pressure viscosity index (Roelands), $\mathrm{z}_{\mathrm{r}}=\mathrm{p}_{\mathrm{r}} \alpha /\left(\ln \left(\eta_{0}\right)+9.67\right)$

$\alpha \quad$ Pressure-viscosity coefficient $\mathrm{Pa}^{-1}$

$\bar{\delta} \quad$ Dimensionless elastic deflection of the contacting bodies

$\bar{\eta} \quad$ Effective viscosities, dimensionless

$\theta \quad$ Angle, rad

$\mu \quad$ Viscosity, Pa.s

$\bar{\mu} \quad$ Dimensionless viscosity

$\mu_{0} \quad$ Ambient temperature zero-pressure viscosity, Pa.s

$\bar{\rho} \quad$ Dimensionless lubricant density

$\rho_{0} \quad$ Ambient temperature and pressure density, $\mathrm{kg} \cdot \mathrm{m}^{-3}$

$\tau_{e} \quad$ Equivalent shear stress, $\mathrm{Pa}$

$\tau_{0} \quad$ Characteristic shear stress of Eyring fluid, $\mathrm{Pa}$

$\overline{\tau_{m}} \quad$ Dimensionless mean shear stress 
Sa Arithmetical mean height of the surface, $\mu \mathrm{m}$

$\mathrm{Sz} \quad$ Maximum height of the surface, $\mu \mathrm{m}$

Sk $\quad$ Reduced peak height of the surface, $\mu \mathrm{m}$

\section{Introduction}

With a stringent legislation for the limitation of harmful polluting emissions, the improvement of environment efficiency of vehicle engine is became a fundamental objective [1]. It is evident actually, based on several experimental and numerical studies, that cylinder engine surface texture considerably influences functional performances (running-in, friction, oil consumption, wear...) of the ring-pack tribo-system [2-4].

Honing is a widely used finishing process for cylinder surfaces after drilling or turning operation to guarantee reproducibility with efficient productivity in mass production of cylinder liners [5]. In honing, abrasive stones are loaded against the bore and simultaneously rotated and oscillated. The industrial honing involves graduated stages of abrasive finishing processes, using at first a coarse abrasive stones, and then progressively finer grades, so that a very structured surface of liner is produced. Characteristically, the resulting structured surface consists of low rough plateau textures separated by two or more bands of parallel deep valleys with stochastic angular position [6].

Hence, effort has been made in last decade for the improvement of honing process for cylinder liners finishing. Moreover, various new surface textures was proposed by the development of innovate honing techniques (slide honing, glide honing, brush honing...) [7$11]$ and surface texturing methods to meet both actual and future functional requirements [12, 13].

Unfortunately, the whole effect of different cylinder liner finishes on ring-pack performance is not well understood [11]. Furthermore, the engineered optimized functional surface is still not well defined. Then, it is important to define the optimum texture characteristics to obtain the best functional properties.

Some topographical and lateral geometric properties of the cylinder bores affect considerably the functional performances of the ring-pack contact, particularly, the crosshatch angle [1418], superficial plateau roughness [19, 20] and the valley and surface patterns depth [14] and density [14]. It believed that liner surfaces that have smaller valleys and smoother plateaus would reduce friction and oil consumption [9]. Moreover, the orientation of micro-grooves has a strong effect on the friction performance of sliding surfaces and optimal orientation is 
closely dependent on the contact conditions [17]. In hydrodynamic lubrication condition, two optimal range of crosshatch angle was determined $\left[40^{\circ}-60^{\circ}\right]$ and $\left[120^{\circ}-140^{\circ}\right]$ [14]. However, [7] shows that the steep honing angle did not present any improvement in ring-pack friction and wear at the top dead center of the cylinder but it yields to less oil consumption over the entire engine course in comparison to $40^{\circ}$ honing angle $[8,10]$.

In this paper, the mutual influence of honing angle and superficial plateau roughness was investigated based on comparison of surface textures generated by two kind of honing processes: the widely used Plateau honing with honing angle in the range of $40^{\circ}-60^{\circ}$ and helical slide honing with grooves arranged in the direction of the piston in an elongated spiral (120-140 honing angle). Thus, to predict friction of the produced textures in ring-pack tribosystem, simulation model in mixed lubrication regime was developed. Then, an algorithm involving the generation of 3D surface topographies with controlled superficial plateau roughness and total surface height is established. Finally, a comparison between these two processes and possible friction reduction strategy in ring-pack system is analysed and discussed.

\section{Numerical model for hydrodynamic friction simulation in piston ring- pack system}

A numerical model was developed to estimate the friction generated between rough surfaces. The model considered the real topography of the cylinder bore surfaces. The objective of this model is to compare the predicted friction coefficient between two kinds of cylinder bore textures in accordance with their superficial plateau roughness amplitude.

\subsection{Elastohydrodynamic equations}

The generalized Reynolds' equation introduced by Najji [21] has been used to estimate the pressure distribution, film thickness, and the friction coefficient. This equation has the advantage of not being restricted to a particular non-Newtonian law. The steady state equation in the dimensionless form is given by:

$$
\frac{\partial}{\partial X}\left\{\frac{\bar{\rho} H^{3}}{\lambda^{\prime}}\left(\frac{1}{\overline{\eta_{e}^{\prime \prime}}}-\frac{\overline{\eta_{e}}}{\overline{\eta_{e}^{\prime 2}}}\right) \frac{\partial P}{\partial X}\right\}+\frac{\partial}{\partial Y}\left\{\frac{\bar{\rho} H^{3}}{\lambda^{\prime}}\left(\frac{1}{\overline{\eta_{e}^{\prime \prime}}}-\frac{\overline{\eta_{e}}}{\overline{\eta_{e}^{\prime 2}}}\right) \frac{\partial P}{\partial Y}\right\}
$$




$$
=\frac{\partial \bar{\rho} H\left(u_{2}-\frac{\overline{\eta_{e}}}{\overline{\eta_{e}^{\prime}}} u_{2}-u_{1}\right)}{\partial X}+\frac{\partial \bar{\rho} H}{\partial T}
$$

where $\lambda^{\prime}=\frac{R^{2} \mu_{0}}{p_{h} a_{h}^{3}}, \frac{1}{\overline{\eta_{e}}}=\int_{0}^{1} \frac{d Z}{\bar{\eta}}, \frac{1}{\overline{\eta_{e}^{\prime}}}=\int_{0}^{1} \frac{Z d Z}{\bar{\eta}}$ and $\frac{1}{\overline{\eta_{e}^{\prime \prime}}}=\int_{0}^{1} \frac{Z^{2} d Z}{\bar{\eta}}$

The effective viscosities could be calculated as considering the shear-thinning effect (Eyring fluid):

$$
\frac{1}{\bar{\eta}}=\frac{1}{\mu} \frac{1}{\overline{\tau_{m}}} \sinh \overline{\tau_{m}}
$$

with $\overline{\tau_{m}}=\tau_{e} / \tau_{0}$, where, $\tau_{0}$ is a reference shear stress and $\tau_{e}=\sqrt{\tau_{x}^{2}+\tau_{y}^{2}}$ is the equivalent shear stress inside the lubricant film.

The lubricant's viscosity and density are assumed to depend on pressure. The Dowson and Higginson formula [22] (Eq. 3) and Roelands law [23] (Eq. 4) were used:

$$
\bar{\rho} P=\left[1+\frac{0.6 \times 10^{-9} P \cdot p_{h}}{1+1.7 \times 10^{-9} P \cdot p_{h}}\right]
$$

where, $\rho_{0}$ is the density at ambient pressure.

$$
\bar{\mu} P=\exp \left(\ln \mu_{0}+9.67\left(-1+\frac{P \cdot p_{h}}{p_{r}}\right)^{z_{r}}\right)
$$

where, $\mu_{0}$ is the viscosity at ambient pressure, $p_{r}$ is a constant equal to $1.96 \times 10^{8}$, and $z_{r}$ is the pressure viscosity index.

Finally, the boundary condition $\mathrm{P}=0$ and the cavitation $\mathrm{P}(\mathrm{X}, \mathrm{Y}) \geq 0 \forall X, Y$ must be satisfied during the simulation.

The film thickness equation is given in dimensionless form by the following equation:

$$
H \quad X, Y, T=H_{0} T+\frac{X^{2}}{2}+\frac{Y^{2}}{2}+\bar{\delta} \quad X, Y, T-\overline{Z_{h}} X, Y, T
$$

Where, $\mathrm{Z}_{\mathrm{h}}$ is the height surface topography at each position $X, Y$ and $\bar{\delta} X, Y, T$ is the dimensionless surface deformation calculated by

$$
\bar{\delta} X, Y, T=\frac{2}{\pi^{2}} \iint_{\Omega} \frac{P X^{\prime}, Y^{\prime}, T d X^{\prime} d Y^{\prime}}{\sqrt{X-X^{\prime^{2}}+Y-Y^{\prime 2}}}
$$

The global force balance condition is given by: 


$$
\frac{2 \pi}{3}=\iint_{\Omega_{c}} P X, Y, T d X d Y \quad \forall T
$$

\subsection{Numerical procedure}

The Reynolds equation was solved by the finite difference method in order to obtain the film pressure distribution. A second order accuracy with respect to both space and time [24], was used. The discredited equation was solved by the Jacobi line relaxation [25]. The full-scale mixed EHL approach developed by $\mathrm{Hu}$ and Zhu [26] was used in the present study. The multi-grid method [25] was applied in order to accelerate the solution convergence. The elastic deformation calculation was conducted by using the discrete convolution and fast integration [25]. The integral terms in the generalized Reynolds' equation were calculated at each step using the solution obtained at the previous stage. A classical Newton-Raphson procedure was used to determine the shear stress and the effective viscosities. The solution domain was determined as $-2.5 \leq X \leq 1.5$ and $-2.0 \leq Y \leq 2.0$. The computational grid covering the domain consisted of equally spaced $512 \times 512$ or $1024 \times 1024$ nodes. Using rough surfaces in EHL simulation could yield localized asperity contact pressure peaks usually higher than the average EHL pressure resulting in high subsurface stress that exceeds the material yielding limit [27]. To limit the contact pressure, the elastic-perfectly plastic behavior of a material was approximately simulated by using a cut-off value, i.e. the hardness of the material. The normal load $\mathrm{F}_{\mathrm{N}}$ and contact speed $\mathrm{u}_{\mathrm{m}}$ are respectively equal to $50 \mathrm{~N}$ and $300 \mathrm{rpm}$ [28]. It simulate the piston ring-cylinder bore contact in mixed regime that occur near the Top Dead Center (TDC) and Bottom Dead Center (BDC) [28].

\section{Mastered honed surface topographies generation}

The honed surface texture of cylinder liners is composed of 3D superficial rough surface separated by deep valleys with defined crosshatch angle. These two elements play different roles in the cylinder-ring contact [29]. The superficial plateau morphology replaces partially initial run-in and related to friction and wear. The valleys component is related to lubricant circulation and retention.

The morphological filtering approach described in [29], provides a powerful tool capable of separating these two principal components of the honed surface topography data. This approach, use an alternate sequential filter with a disc structuring element, as non-linear image processing operator. The surface topography is filtered recursively with increasing the filter size after each filtering operation until reach the smallest form elements. Figure 1 shows 
an example of decomposition of plateau honed surface topography. Then, the two fundamental parts of the cylinder surface (Superficial plateau and valleys components) are characterized by theirs root-mean square height respectively $S_{p q}$ and $S_{v q}$. These parameters are mutually independent.
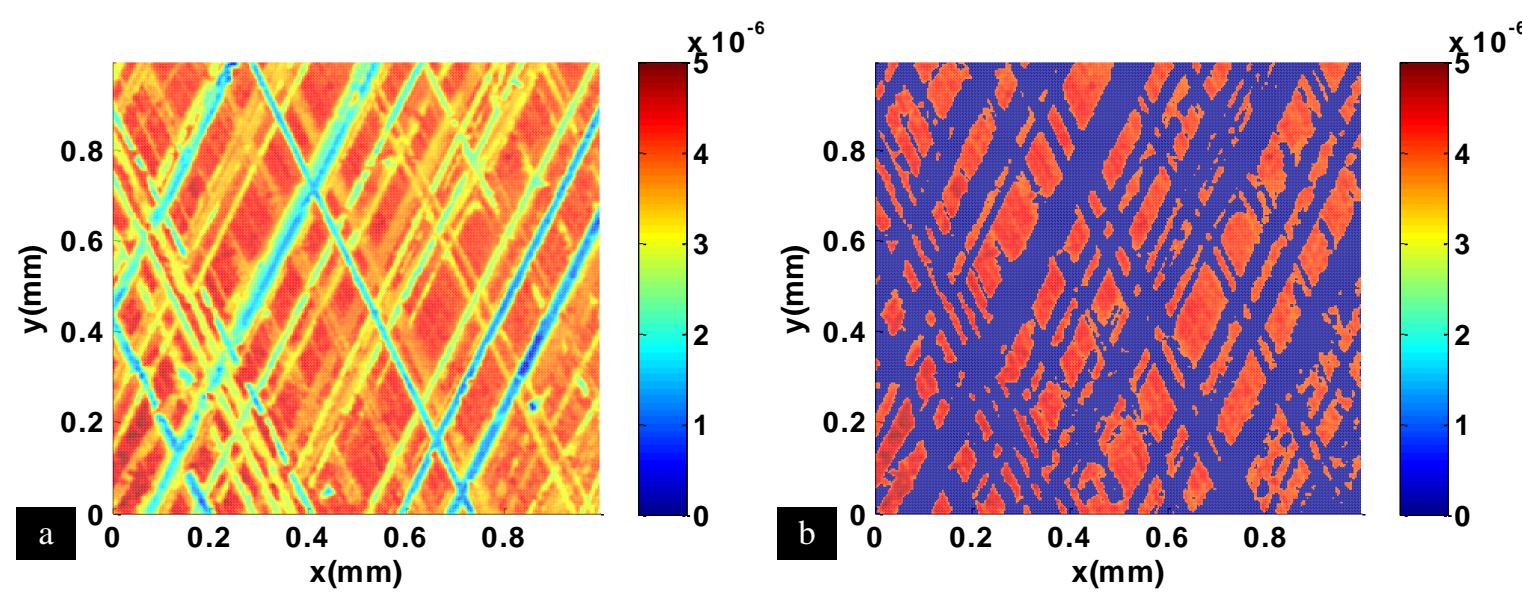

Figure 1 Example of decomposition of a cylinder liner surface topography using alternate sequential filtering; (a) tri-dimensional topography of plateau honed surface, (b) superficial plateau (in red) and valleys components (in blue).

To investigate the mutual effect of crosshatch angle and the plateau surface roughness on frictional losses at the interface between a piston ring and cylinder liner, an approach for generating controlled surface topography based on real surface measurement data was developed. The algorithm of the method used for surface topographies generation is described in Figure 2. It is applied for creation of surface topographies with different specified amplitude ratio plateau/valleys and having the same total surface height Sz (ISO 25178-2 standard) from two original honed surfaces plateau honed (PH) and helical slide honed (HSH) surfaces taken from mass production of cylinder liners (Figure 3).

Plateau honing very widely used process is a succession of three honing stages $[5,6]$. The first stage often categorized as rough honing establishes the form of the bore. The so called "finish honing" which creates the basic surface texture of the hole is the second operation. This enables the third honing operation - plateau stage - to serve for removing the surface peaks, increasing plateau surface area and then reducing the plateau valleys amplitude ratio.

HSH is achieved with the same stages succession but generate surface with steep honing crosshatch angle by reducing the rotational speed of the honing tool and increasing the stroke rate to limit the reduction in the stroke removal rate. 


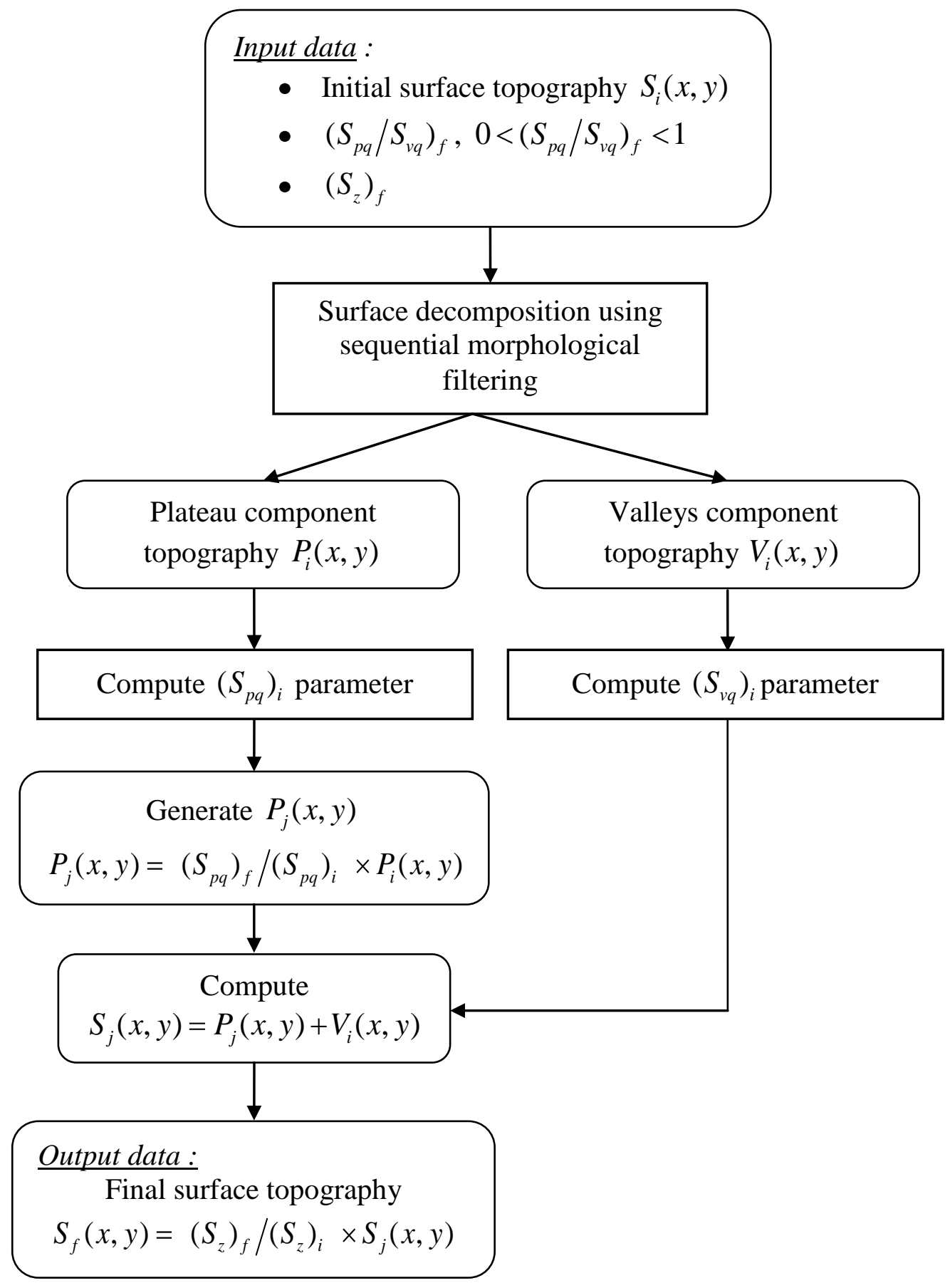

Figure 2 Algorithm of reconstruction of honed surfaces with mastered plateau/valleys amplitude ratio and total surface height (Sz) from a original honed surface texture.

The principal difference between the real $\mathrm{PH}$ and $\mathrm{HSH}$ surface textures is the honing angle between the two groove orientations, the maximum height of the surface and the plateau valleys amplitude ratio. For considered surfaces (Figure 3), the honing angle is about $50^{\circ}$ for $\mathrm{PH}$ surface and is beyond $130^{\circ}$ for HSH surface, the ratio $\frac{S_{p q}}{S_{v q}}$ is equal to 0.62 for the original 
plateau honed surface and 0.54 for the original helical slide honed surface. These two surface textures have almost the same texture aspect parameters that affect friction such as grooves density $\left(\approx 600\right.$ grooves $\left./ \mathrm{mm}^{2}\right)$ and grooves balance $(\approx 0.5)$. The method of quantification of these lateral texture characteristics and theirs influence on friction are detailed in $[6,14]$.

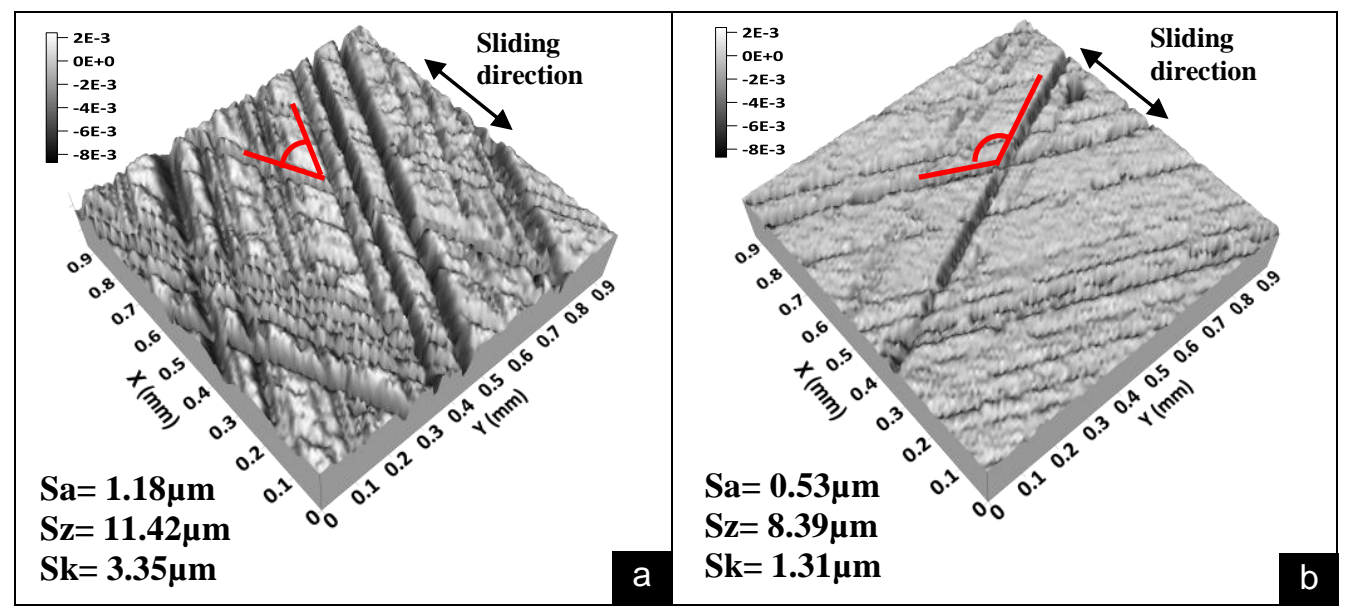

Figure 3 Three-dimensional topographies of typical (a) plateau-honed surfaces and (b) helical slide honing surface showing a different cross-hatch angle respectively $50^{\circ}$ and $130^{\circ}$.

Using this methodology, the comparison between surface textures generated by plateau honing and helical slide honing is performed with the same total surface height $(\mathrm{Sz})$. Moreover, all surface feature characteristics (groove density, groove width,...) are realistic and remains unchanged. Three total surface height $(\mathrm{Sz}=2.5 \mu \mathrm{m}, \mathrm{Sz}=5 \mu \mathrm{m}$ and $\mathrm{Sz}=10 \mu \mathrm{m})$ and six plateau/valleys amplitude ratio between 0.1 and 0.8 were considered. A ratio equal to 0 corresponds to an "ideal" smooth plateaued surface. A ratio equal to 1 represents a nonplateaued surface finish.

\section{Results and discussion}

The numerical model presented in Section 2 was used to predict friction in the ring-linerpiston contact and to analyze the mutual effect of crosshatch angle and superficial plateau roughness on friction.

Figure 4 and Figure 5 resume the obtained simulation results performed in this study.

Figure 4 depicts the influence of superficial plateau roughness on friction coefficient of PH (50 honing angle) and HSH (130 ${ }^{\circ}$ honing angle) cylinder liner surfaces for three level of liner surface roughness Sz. One can see that, in mixed lubrication conditions, friction coefficient $(\mathrm{COF})$ increases with increasing liner surface roughness for both $\mathrm{PH}$ and HSH 
honed surfaces. In this lubrication regime, friction is reduced by at least $36 \%$ when cylinder bores were finished by helical slide honing in comparison to plateau honing finish.
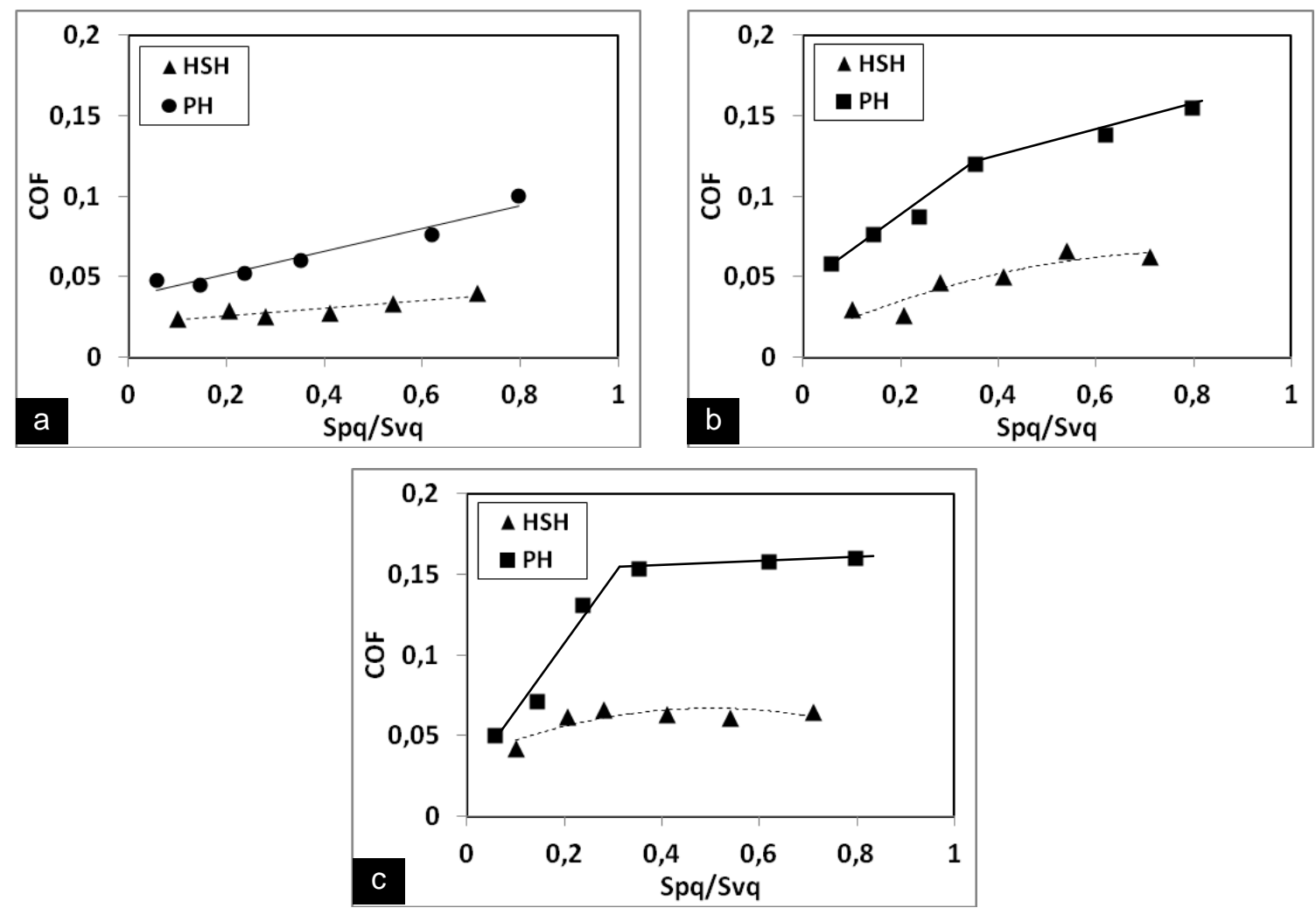

Figure 4 Friction Coefficients of $\mathrm{PH}$ and $\mathrm{HSH}$ cylinder liner surfaces function of the ratio $\mathrm{Spq} / \mathrm{Svq}$ and for three different total surface height (a) $\mathrm{Sz}=2.5 \mu \mathrm{m}$, (b) $\mathrm{Sz}=5 \mu \mathrm{m}$ and (c) $\mathrm{Sz}=10 \mu \mathrm{m}$.

Moreover, as shown in Figure 5 which shows the evolution of metal to metal contact and the average film thickness between the friction pairs function of the plateau/valleys amplitude ratio, steep honing angle $\left(130^{\circ}\right.$ crosshatch angle) reduce the oil film thickness average and leads to lower dry contact area and tightens therefore to a hydrodynamic lubrication regime.

The frictional performance of helical slide honed cylinder is three times less sensitive to superficial plateau roughness (Figure 4). Table 1 resumes the rate of friction variation function of plateau-valleys ratio for $\mathrm{PH}$ and HSH surfaces. Plateau honed surfaces are very sensitive to superficial plateau roughness particularly when $\frac{S_{p q}}{S_{v q}} \leq 0.3$ for $S z \geq 5 \mu m$ (Figure 4). Therefore, the third honing stage in plateau honing process has a decisive influence since it allows to reduce considerably friction by reducing plateau roughness amplitude. Furthermore, 
this reduction of superficial plateau peaks yields to diminish the metal to metal contact area and thereby to less lubricant film dislocation.
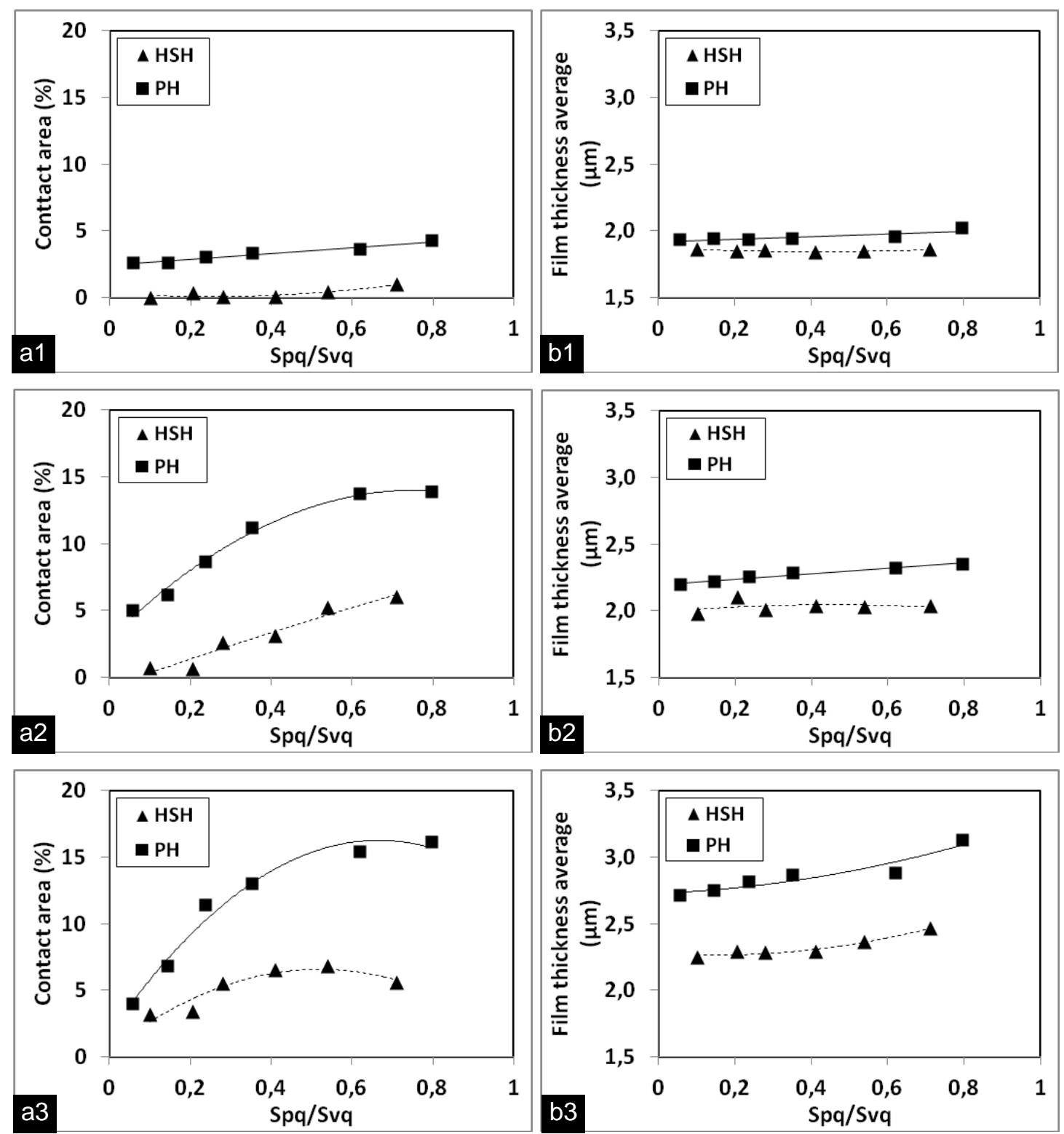

Figure 5 Contact area ratio (a) and film thickness average (b) of $\mathrm{PH}$ and $\mathrm{HSH}$ cylinder liner surfaces function of the ratio Spq/Svq and for three different total surface height (1) $\mathrm{Sz}=2.5 \mu \mathrm{m},(2) \mathrm{Sz}=5 \mu \mathrm{m}$ and (3) $\mathrm{Sz}=10 \mu \mathrm{m}$.

In contrary, Surface textures with $140^{\circ}$ cross-hatch angles are very less sensitive to superficial surface peaks in particular with $S z \leq 5 \mu m$ (Table 1). Therefore, this third honing operation can be canceled in production process of HSH surface textures. So, with only two-stage honing operations, more efficient production of cylinder liners at industrial level is guaranteed. Finally, optimal surface texture is characteristically defined by steep honed angle with 
$S z \leq 5 \mu \mathrm{m}$. It yields to the lower friction and oil film thickness average and with dry contact area less than $2 \%$.

Table 1. Rate of friction variation function of plateau-valleys ratio changes

\begin{tabular}{|c|c|c||c|c|}
\hline Surface total height & \multicolumn{2}{|c||}{ PH } & \multicolumn{2}{c|}{ HSH } \\
\hline $\mathbf{S z}=\mathbf{2 . 5} \boldsymbol{\mu m}$ & \multicolumn{2}{|c|}{$7.13 \%$} & \multicolumn{2}{c|}{$2.44 \%$} \\
\hline & $\frac{S_{p q}}{S_{v q}} \leq 0.3$ & $\frac{S_{p q}}{S_{v q}}>0.3$ & $\frac{S_{p q}}{S_{v q}} \leq 0.3$ & $\frac{S_{p q}}{S_{v q}}>0.3$ \\
\hline $\mathbf{S z}=\mathbf{5} \boldsymbol{\mu m}$ & $20.28 \%$ & $7.78 \%$ & $7.8 \%$ & $4.3 \%$ \\
\hline $\mathbf{S z}=\mathbf{1 0} \boldsymbol{\mu m}$ & $45.3 \%$ & $1.6 \%$ & $13.8 \%$ & $0.3 \%$ \\
\hline
\end{tabular}

\section{Conclusion}

The mutual effect of crosshatch angle and superficial plateau roughness of honed surface textures of cylinder liners in mixed lubrication contact regime was investigated. Then, two real honed surface textures produced respectively by plateau honing ( $50^{\circ}$ honing angle) and helical slide honing $\left(130^{\circ}\right.$ honing angle) were considered. An algorithm for generation of surface topographies with mastered plateau/valleys amplitude ratio and specified total surface height from real three-dimensional surface data was developed. Then, the friction performance of a cylinder ring-pack system in mixed lubrication regime was predicted. Finally, results of numerical simulations show that:

1. For $50^{\circ}$ honing angle and surface total height greater than $10 \mu \mathrm{m}$, the reduction of the superficial plateau roughness decreases considerably the friction in mixed lubrication contact regime;

2. The $130^{\circ}$-honed liner (helical slide honing) leads to an improvement in friction, film thickness and reduce the dislocation of the boundary layer in comparison to $50^{\circ}$ crosshatch angle (plateau honing);

3. With helical slide honed liners, friction is much less sensitive to superficial plateau roughness than with plateau honed liners. Then, the industrial helical slide honing process can be set up in only two process stage instead of the three stage required for plateau honing in mass production of cylinder engines. 


\section{References}

[1] Sabeur M., Ibrahim D., Mohamed E.M., Hassan Z. Energy efficiency optimization of engine by frictional reduction of functional surfaces of cylinder ring-pack system. Trib Int. $2013 ; 59: 240-247$.

[2] Pawlus P. Effects of honed cylinder surface topography on the wear of piston-piston ringcylinder assemblies under artificially increased dustiness conditions. Trib Int 1993; 26(1):4955.

[3] Shinkarenko A, Kligerman Y, Etsion I. The effect of surface texturing in soft elastohydrodynamic lubrication. Trib Int 2009; 42 (2):284-292.

[4] Jocsak J, Wong V.W, Tian T. The Effects of Surface Finish on Piston Ring-pack friction. Proceedings of the 2004 Fall Technical Conference of the ASME Internal Combustion Engine Division; 2004, p. 841-849.

[5] Sabri L, Mezghani S, El Mansori M, Zahouani H. Multiscale study of finish-honing process in mass production of cylinder liner. Wear 2011; 271:509-13.

[6] Sabri L, Mezghani S, El Mansori. Functional optimisation of production by honing engine cylinder liner. Méca et indus 2010; 11(5):365-77.

[7] Johansson, S., Nilsson, P.H., Ohlsson, R., Anderberg, C., Rosén, B-G. New cylinder surfaces for low oil consumption, Trib Int 2008; 41 (9-10):854-859.

[8] Haasis G, Weigmann U.-P. New honing technique reduces oil consumption, Indus Diamond Rev 1999; 59, no582, p. 205-211, ISSN 0019-8145.

[9] Dimkovski Z and al. Optimization of cylinder liner surface finish by slide honing Manufacture. Proc. IMechE, Part B: J. Eng. Manufac. 2010; 226(4):575-584.

[10] Hoen T., Schmid J., Stumpf W. Less Wear and Oil Consumption trough Helical Slide Honing of Engines by Deutz, MTZ 04I2009 ; 70:46-51.

[11] Tomanik E. Friction and wear bench tests of different engine liner surface finishes. Trib Int; 200841 (11):1032-1038.

[12] Ma C., Zhu H. An optimum design model for textured surface with elliptical-shape dimples under hydrodynamic lubrication. Trib Int 2011; 44 (9):987-995.

[13] Kovalchenko A., Ajayia O., Erdemir A., Fenske G., Etsion I. The effect of laser surface texturing on transitions in lubrication regimes during unidirectional sliding contact. Trib Int 2005; 38 (3):219-225.

[14] Mezghani S., Demirci I., Zahouani H., El Mansori M. The effect of groove texture patterns on piston-ring pack friction. Precis Eng 2011; 36 (2):210-217. 
[15] Jocsak J., Li Y., Tian T., Wong V.W. Analyzing the effect of three dimensional cylinder liner surface texture on ring-pack performance with a focus on honing groove cross-hatch angle, 2005 Fall Technical Conf. ASME Internal Combust. Engine Divis; 2005, p. 621-632.

[16] Shi X., Ni T. Effects of groove textures on fully lubricated sliding with cavitation. Trib Int 2011; 44 (12):2022-2028.

[17] Yuan S., Huang W., Wang X. Orientation effects of micro-grooves on sliding surfaces. Trib Int 2011; 44 (9):1047-1054.

[18] Křupka I., Perka P., Hartl M., Xue Jin S., Xiao Yang C. Effect of real longitudinal surface roughness on lubrication film formation within line elastohydrodynamic contact. Trib Int 2010; 43 (12):2384-2389.

[19] Larsson R. Modelling the effect of surface roughness on lubrication in all regimes. Trib Int 2009; 42 (4):512-516.

[20] Demirci I, Mezghani S, Yousfi M, Zahouani H, El Mansori M. The scale effect of roughness on hydrodynamic contact friction. Trib Trans 2012; 55(5): 705-712.

[21] Najji B., Bou-Said B., Berthe D. New Formulation for Lubrication with Non-Newtonian Fluids. J. Tribol. 1989; 111:29-33.

[22] Dowson, D., and Higginson, G.R. Elastohydrodynamic Lubrication; The Fundamentals of Roller and Gear Lubrication. Pergamon, Oxford 1966.

[23] Roelands CJA. Correlational aspects of the viscosity-temperature-pressure relationships of lubricant oil. Doctoral Thesis, Technische Hogeschol Delft, Nederlands 1966.

[24] Venner C.H, Morales-Espejel G.E. Amplitude reduction of small-amplitude waviness in transient elastohydrodynamically lubricated line contacts. Proc Instn Mech Engrs Part J. 1999; 213:487-504.

[25] Venner C.H., Lubrecht A.A. Multilevel methods in lubrication. Elsevier, The Netherlands 2000.

[26] Hu Y.Z., Zhu D. A full numerical solution to the mixed lubrication in point contacts. J. Tribol. 2000; 122:1-9.

[27] Ren N., Zhu D., Chen W.W., Wang Q.J. Plasto-elastohydrodynamic lubrication (PEHL) in point contacts. J. Tribol. 2010; 132 (3):1-11.

[28] Bolander N.W., Steenwyk B.D., Sadeghi F. and Gerber G.R. Lubrication regime transitions at the piston ring-cylinder liner interface, Proc. IMechE Part J, J. Eng Trib, 2005; 219(1):19-31. 
[29] Decencière E, Jeulin D. Morphological decomposition of the surface topography of an internal combustion engine cylinder to characterize wear. Wear 2001; 249 (5-6):482-488. 